\title{
Arkeologi Kawasan Dan Kawasan Arkeologis: Asas Keseimbangan Dalam Pemanfataan
}

\section{Timbul Haryono}

Keywords: spatial, area, macro, micro, sites, cultural resource management

\section{How to Cite:}

Haryono, T. Arkeologi Kawasan Dan Kawasan Arkeologis: Asas Keseimbangan Dalam Pemanfataan. Berkala Arkeologi, 15(3), 139-143. https://doi.org/10.30883/jba.v15i3.686

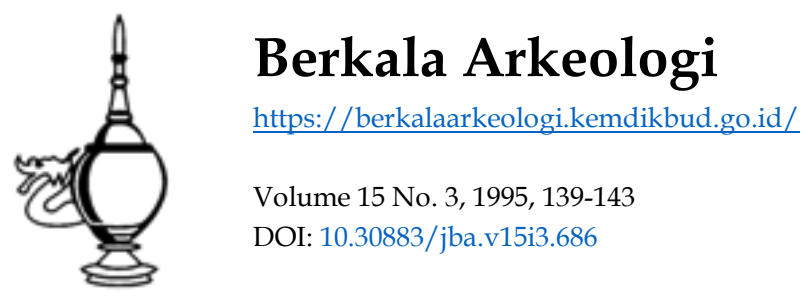

\section{(1) (2) (-)}

This work is licensed under a Creative Commons Attribution-NonCommercialShareAlike 4.0 International License. 


\title{
ARKEOLOGI KAWASAN DAN KAWASAN ARKEOLOGIS: ASAS KESEIMBANGAN DALAM PEMANFATAAN
}

\author{
Timbul Haryono \\ (Jurusan Arkeologi FS-UGM)
}

\begin{abstract}
The archaeological profession is today presented with more challenges and opportunities than at any time in its history. It also faces its gravest peril. The opport-unities are to ensure that archaeological (and all cultural) resources are incorpo-rated in public and increasingly in private planning, that decisions concerning those resources are made in the context of the total public good and are based on adequate information,
\end{abstract}

(McGimsey III, 1978:418)

\section{Pengantar}

Pernyataan di atas sengaja dikutip untuk mengawali karangan ini dengan maksud untuk dipakai sebagai peringatan terhadap arkeologi di Indonesia yang, pada hemat penulis, juga mengalami banyak tantangan dan kesempatan. $\mathrm{Pa}$ da masa sekarang ini, sebagai akibat perkembangan ilmu arkeologi di Amerika dan di Eropa, arkeologi di indonesia harus "outward looking orientation. Sikap yang "inward looking" sudah tidak lagi sesuai dan bahkan mungkin akan mengakibatkan arkeologi Indonesia akan ketinggalan.

Dengan outward looking orientation dimak-sudkan arkeologi Indonesia harus berorientasi keluar sesuai dengan perkembangan jaman dan tuntutan masyarakat. Harus disadari meskipun arkeologi itu mempelajari masa lampau akan te-tapi tidak berarti para pakar arkeologi hanya ber-henti pada: "mengetahui masa lampau". Sete-rusnya harus dihubungkan dengan masa seka-rang dan masa yang akan datang. Dalam kon-sep: atita-nagata-warttamana terdapat jalinan kai-tan yang erat antara masa lampau, masa seka-rang, dan masa yang akan datang (Sukarto K. Atmodjo, 1986:48).

Masyarakat sekarang ini bersifat majemuk. Di antara kelompok-kelompok masyarakat ada yang berorientasi pada masa kini, ada pula yang berorientasi pada masa mendatang, namun tidak sedikit pula masyakat yang berorientasi pada masa lampau. Selain itu tingkat kompleksitas masyarakat membawa perbedaan pada cara pandang terhadap kaitan masa lalu dengan masa kini dan masa akan datang (Daud Aris Tanudirjo dkk. 1993/1994:9).
Arkeologi bukan semata-mata hanya mempelajari masa lampau saja. Charles R. McGimsey III (1978:417) menegaskan: "It has often been said that archaeology is the study of Othe past - and so it is, but it is far more than that. Archaeo-logy encompasses a total concern for the hu-man past and for ensuring that a maximum amount of information meaningful to present and future generations is derived from that past and made available to those generations. This entails a great deal more than just studying the past."

Arkeologi harus dapat dimanfaatkan untuk kepentingan masa sekarang dan masa akan da. tang, untuk generasi sekarang dan akan datang. Pertanyaan selanjutnya adalah: siapa yang berkepentingan memanfaatkan hasil studi arkeologi. Kertas kerja ini berusaha untuk membahas masalah pemanfaatan hasil studi arkeologi secara singkat, khususnya dalam hal kawasan arkeologis dengan pokok bahasan pada azas keseimbangan

\section{Arkeologi Kawasan dan Kawasan Arkeologis}

Studi tentang Arkeologi Kawasan dilandasi suatu pemikiran bahwa aspek ruang merupakan bagian yang tak terpisahkan dalam hidup manusia. Studi arkeologi mencakup 3 dimensi: dimensi bentuk, ruang, dan waktu. Ketiga dimensi tersebut merupakan unit dasar dalam formulasi unit arkeologis yang harus dikombinasikan untuk sampai pada tujuan studi arkeologi. Menurut Willey dan Phillips (1959:18) ciri fundamental semua formulasi unit arkeologis adalah harus sampai pada kombinasi 3 jenis data tentang bentuk artefak, distribusinya di dalam ruang geografis, dan durasi waktu.

Meskipun studi arkeologi mempelajari masa lampau manusia berdasarkan atas benda-benda yang ditinggalkan, namun dalam pelaksanaannya studi arkeologi tidak cukup hanya berorientasi pada artefak saja. Artefak tinggalan manusia masa lampau tidak dapat dipisahkan dengan konteks ruang, baik dalam skala mikro maupun makro.

Kawasan arkeologis di dalamnya mengandung tinggalan-tinggalan budaya manusia yang harus diamankan dan dilindungi. Selain itu juga harus dimanfaatkan untuk kepentingan umum. $\mathrm{Di}$ dalam pasal 14 Undang-undang RI no. 4 tahun 
1982 tentang Ketentuan-ketentuan Pokok Pengelolaan Lingkungan Hidup dinyatakan bahwa warisan budaya adalah salah satu unsur lingkungan hidup yang harus dilindungi. Dengan demikian dalam pengelolaannya tetap harus berpegang pada prinsip perlindungan, pengamanan, dan pelestarian. Kawasan arkeologis maupun kandungan materialnya merupakan sumberdaya budaya yang amat bermanfaat untuk masyarakat, baik masyarakat ilmiah maupun masyarakat umum

Warisan budaya juga harus berfungsi untuk masa kini maupun masa akan datang. Disinilah kadang kala terjadi konflik kepentingan di antara pihak-pihak yang berkepentingan (Bugie Kusumohartono,1994). Pada dewasa ini kesadaran masyarakat akan arti penting warisan budaya mulai tumbuh berkembang. Dengan demikian kelompok pakar arkeologi sebagai pihak pengelola warisan budaya tidak dapat berorientasi sematamata hanya untuk kepentingan arkeologi sebagai ilmu. "It is not just archaeologists who value knowledge of the past", demikianlah Robert Layton menegaskan (Layton, 1989:1).

\section{Pemanfaatan Tinggalan Arkeologis sebagai Sumberdaya Budaya}

Pernyataan tegas Robert Layton sebagaimana dikutip di muka menunjukkan bahwa setiap anggota masyarakat berhak pula untuk menghargai betapa pentingnya pengetahuan tentang masa lampau. Kenyataannya, kadang-kadang para pakar arkeologi yang seharusnya membantu masyarakat memahami dan memanfaatkan warisan budaya hanya memanfaatkannya untuk kepentingan dirinya sendiri baik secara ilmiah maupun secara finansial:

"Tidak jarang, hasil-hasil penelitian tidak diterbitkan secara luas, bahkan terabaikan di gudang-gudang penelitian. Sebagai akibatnya, masyarakat tidak memperoleh manfaat apa pun dari penelitian itu. Pada hal, pada umumnya penelitian arkeologi dibiayai oleh pemerintah yang memperoleh dana dari masyarakat. Lagi pula penelitian arkeologi itu sendiri pada hakekatnya mengurangi dan bahkan dapat merusak sumberdaya budaya yang ada. Dengan demikian masyarakat akan sangat dirugikan" (Daud Aris Tanudirjo dkk. 1993/1994:12).

Persoalannya sekarang siapa saja yang perIu terlibat di dalam pemanfaatan sumberdaya budaya tersebut. Beberapa pendapat menyatakan ada tiga kubu yang harus dilibatkan dalam pemanfaatan sumberdaya budaya, yaitu para pakar atau akademika, pemerintah, dan masyarakat. (Daud Aris Tanudirjo dkk., 1993/1994; MacLeod, 1977). Jika dilihat dari sudut kepentingan, masing-masing kelompok akan mempunyai kepenti- ngan yang berbeda. Di sinilah, sering terjadi konflik kepentingan baik konflik semu maupun kon-flik nyata (Untoro Dradjat, 1995).

Ketiga kelompok pengelola warisan budaya tersebut satu sama lain seharusnya saling berkaitan seperti berikut

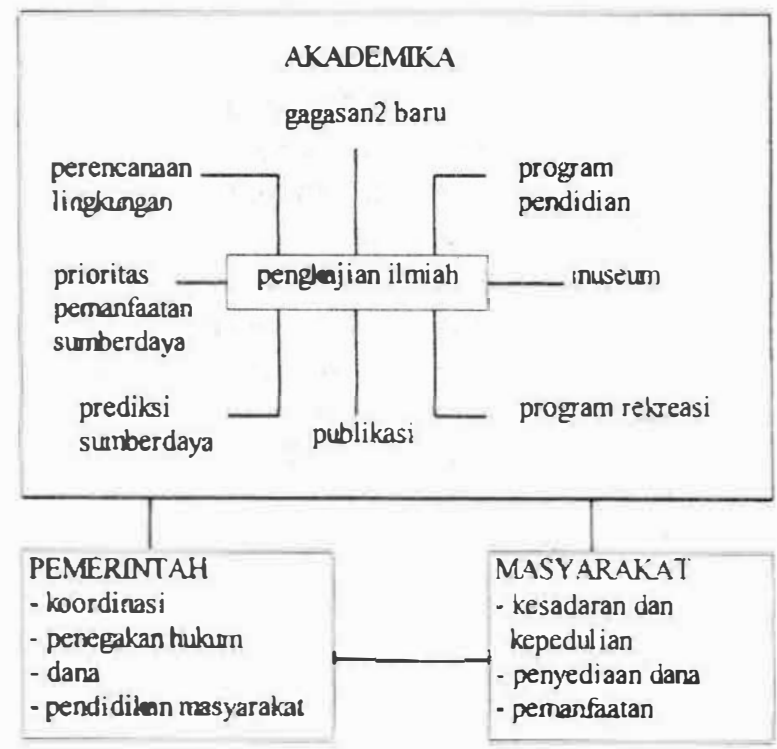

Diagram Hubungan antar kubu dalam pengelolaan warisan budaya

(Sumber: Daud Aris Tanudirjo, 1993/1994:15)

Lingkungan akademika mengungkapan pengetahuan masa lalu secara ilmiah melalui penelitiannya. Hasil penelitian tersebut harus memberikan masukan kepada pemerintah dalam me. ngelola sumberdaya budaya. Pemerintah mempunyai otoritas dalam pengelolaan sumberdaya budaya karena mempunyai kekuatan hukum, dana, serta perangkat hukum yang diperlukan untuk penyelamatan, perlindungan, dan pemanfaatan warisan budaya. Pemerintah juga berkuajiban untuk menyelenggarakan pendidikan kepada masyarakat yang berkaitan dengan apresiasi terhadap warisan budaya. Sementara itu masyarakat memegang hak atas pemanfaatan warisan budaya (Daud Aris Tanudirjo dkk., 1993/1994:16).

Dengan demikian maka diperlukan keterpaduan antar institusi dan kesatuan wawasan manajemen dalam pengelolaan sumberdaya budaya. Manajemen sumberdaya budaya yang berkaitan dengan berbagai kepentingan sangat dibutuhkan dalam upaya melestarikan dan memanfaatkan sumberdaya budaya (Untoro Dradjat, 1995). Hal tersebut dilakukan agar benturan kepentingan berbagai pihak dapat dihindari.

Kawasan arkeologis dengan berbagai bentuk budaya materialnya mempunyai kelebihan untuk dimanfaatkan dalam kepentingan seperti: kepentingan akademik, pendidikan, dan rekreasi. 
Namun harus disadari bahwa dalam pelaksanaan pemanfaatannya dapat berakibat negatif terhadap sumberdaya budaya itu sendiri: "The archaeological resource can be exploi-ted for variety of purposes: academic, educational or recreational. Such uses almost inevitably alter the character of the site and sometimes contribute to its site decay or des-truction" (ICAHM 1988:326, dikutip dari Untoro Dradjat, 1995:9).

Perlu diingat bahwa tinggalan arkeologis mempunyai beberapa sifat keterbatasan seperti misalnya, tak terbaharui (non renewable), mudah rapuh (fragile), terbatas jumlahnya, serta terbatas dalam kemampuannya bertahan terhadap waktu. Sifat keterbatasan seperti tersebut akan sangat berdampak pada cara pemanfaatannya.

Oleh karena itu pemanfaatan kawasan arkeologis sebagai sumberdaya budaya tetap harus berwawasan pelestarian dan perlindungan. Pada pasal 19 UU No. 5 Tahun 1992 dengan tegas dinyatakan bahwa benda cagar budaya tertentu dapat dimanfaatkan untuk kepentingan agama, sosial, pariwisata, pendidikan, ilmu pengetahuan, dan kebudayaan. Namun pemanfaatan seperti tersebut tidak dapat dilakukan apabila bertentangan dengan upaya perlindungan benda cagar budaya dan semata-mata untuk mencari keuntungan pribadi atau golongan.

Pada era pembangunan saat ini sering terjadi perbedaan kepentingan yang tidak jarang mengancam kelestarian benda cagar budaya, khususnya benda cagar budaya tidak bergerak. Selain itu juga masih dirasakan adanya berbagai usaha yang mengarah kepada penggelapan terhadap benda cagar budaya terutama yang bergerak (Sedyawati, 1994).

Ada dua permasalahan yang dilematis dalam pembangunan fisik dewasa ini. Di satu pi-hak, pembangunan itu memerlukan lahan untuk mendirikan bangunan prasarana/sarana umum. Di lain pihak, pembangunan tersebut sering mengakibatkan bangunan aset budaya menjadi rusak, tergusur, atau berubah fungsi (Sedyawati, 1994). Oleh karena itu pemanfaatan yang berwawasan pelestarian dan perlindungan hanya dapat terlaksana apabila masing-masing yang berkepentingan menerapkan azas keselarasan dan keseimbangan (Bugie Kusumohartono, 1994). Kepentingan masing-masing kelompok diselaras-kan satu sama lain sehingga tidak ada penon-jolan kepentingan di masing- masing pihak.

Dengan demikian kepentingan masing-masing kelompok akan seimbang, satu sama lain tidak saling dirugikan. Pemanfaatan untuk pariwisata jangan sampai merugikan kepentingan agama, pendidikan, sosial, dan ilmu pengetahuan. Hal ini dapat terasa pada bangunan-ba- ngunan keagamazn yang termasuk sebagai kelompok "monumen hidup" (living monument). Pada bangunan keagamaan, pemanfaatannya untuk pariwisata harus dilakukan dengan hati-hati agar ketenangan masyarakat dalam melakukan aktivitas keagamaan tetap terjaga. Demikian pula sebaliknya misalnya, pemanfaatan kepentingan untuk ilmu pengetahuan dan pendidikan jangan mengurangi atau merugikan kepentingan sosial, pariwisata.

Kepariwisataan di indonesia akhir-akhir ini berkembang cukup pesat. Pada umumnya objekobjek pariwisata memanfaatkan objek-objek arkeologi. Sebagai contoh misalnya kawasan arkeologis di Borobudur, di Prambanan, di Sangiran. Perkembangan kepariwisataan yang begitu pesat harus dibarengi dengan pengelolaan yang tepat sehingga tidak berdampak negatif terhadap sumberdaya budaya maupun lingkungannya. Bagaimanapun juga, apabila kegiatan pariwisata budaya akan dijadikan komoditas maka dalam implementasinya harus tetap di dalam kerangka kerja penyelamatan warisan budaya sebagai kekayaan budaya bangsa (Sri Sultan Hamengkubuwono X,1992:20) Len Gertler (1992: 12) menyatakan: "A program of cultural tourism has to be guided by a model that takes the form of a positive feedback loop in which coordinated marketing and management activities create a process of mutually reinforcing economic and cultural benefits".

Sangatlah tepat bahwa pada seminar internasional tentang pariwisata budaya 1992 yang lalu telah dicetuskan "Deklarasi Yogyakarta" (The Yogyakarta Declaration on National Cultures and Universal Tourism). Di dalam deklarasi tersebut antara lain dinyatakan (Joop Ave, Hillig, Koesnadi Hardjasoemantri, 1992):

1. The relationship between tourism and the natural and cultural environment must be managed so that the environment is sustainable in the long term. While recognizing that tou-rism can be a positive activity. it must not be allowed to damage the resource, prejudice its future enjoyment or bring an unacceptable impact.

2. In any location, harmony must be sought between the needs of the visitor, the place, and the community.

3. Tourism development should be guided by a planning process involving broad community participation which ensures a proper balance between economic, social, and human objectives.

4. The success of any proposed action is depended on the interrelationship of government, the host communities, and the tourism industry. 
Cukup jelas bahwa ada kerangka acuan pemanfaatan sumberdaya budaya untuk pengembangan kepariwisataan. Di dalamnya ditegaskan adanya azas keselarasan dan kesimbangan. Permasalahannya adalah implementasinya di lapangan, adakah sudah sesuai dengan kerangka acuan yang ada. Hal ini sekali lagi tergantung pada para pelaksana yang terlibat di dalamnya.

Dalam perkembangan pembangunan fisik, khususnya yang menyangkut masalah peningkatan sarana dan prasarana seperti jalan, tempattempat pemukiman, memerlukan lahan yang sering kali berdekatan dengan sumberdaya budaya. Bahkan mungkin sekali di dalam tanah yang dipakai sebagai lahan pembangunan fisik tersebut terdapat tinggalan arkeologis. Dengan demikian perlu pengecekan terlebih dahulu secara arkeologis melalui studi kelayakan. Pada kasus yang demikian ini kadang-kadang masih ada anggapan yang keliru bahwa penelitian arkeologis tersebut merupakan penghambat pembangunan. Disadari atau tidak, para pakar arkeologi masih sering berorientasi pada kepentingan arkeologis semata. Di lain pihak, dalam pengembangan perkotaan bangunan-bangunan yang masih mempunyai nilai arkeologis dan historis kadang-kadang juga masih menjadi objek perbedaan dan pertentangan kepentingan. Untuk itu diperlukan persamaan persepsi tentang kaidah pemanfaatan sumberdaya budaya sehingga antara usaha pelestarian dan pemanfaatan dapat berjalan seiring.

\section{Penutup}

Berdasarkan uraian di muka dapatlah disimpulkan beberapa pokok pemikiran bahwa kawasan arkeologis dengan segala isinya merupakan sumberdaya budaya yang sangat penting untuk menunjang pembangunan dewasa ini. Sumberdaya budaya tersebut dapat dimanfaatkan untuk kepentingan pendidikan, rekreasi, maupun untuk kepentingan masyarakat umum. Pemanfaatan sumberdaya budaya tetap harus berwawasan pada pelestarian dan perlindungan.

Mengingat kelompok-kelompok yang terlibat di dalam pemanfaatan sumberdaya budaya mempunyai kepentingan yang satu sama lain berbeda, maka azas keseimbangan dan keselarasan dalam pemanfaatan harus dijadikan sebagai dasar pijakan. Dengan demikian akan dapat dihindari konflik kepentingan yang dapat menimbulkan dampak negatif terhadap kelestarian dan keamanan sumberdaya budaya.

Terima kasih disampaikan kepada Drs. Bugie Kusumohartono dan Drs. Kusen atas sarannya untuk penulisan makalah ini.

\section{KEPUSTAKAAN}

Bugie Kusumohartono.1994. Makna Penting Situs Sangiran: Dukungan Dari Segi Penataan Ruang. Evaluasi Hasil Studi Teknis Pengembangan Cagar Budaya Sangiran. Surakarta: Ditlinbinjarah

Daud Aris Tanudirjo dkk. 1993/94. Kualitas Penyajian Warisan Budaya Kepada Masyarakat: Studi Kasus Manajemen Sumberdaya Budaya Candi Borobudur Laporan Penelitian. Yogyakarta: PAU Studi Sosial UGM

Gertler, Len.1992.Revitalizing the Cultural Heritage. Dalam Yoop Ave, Jurgen Hillig, Koesnadi Hardjasoemantri (ed.). Universal Tourism Enriching or Degrading Culture? Yogyakarta: Gadjah Mada University Press

Hamengku Buwono X,Sri Sultan.1992.Revitalization of Cultural Heritage within the Context of Tourism, Dalam Yoop Ave, Jurgen Hillig. Koesnadi Hardjasoemantri (ed.) Universal Tourism Enriching or Degrading Culture? Yogyakarta: Gadjah Mada University Press

Layton, Robert (ed.). 1989. Who Needs the Past. London: Unwin Hyman.

MacLeod, Donald G.1977.Peddle or Perish: Archaeological marketing from concept to product delivery. Dalam Michael Schiffer dan George J. Gummerman (eds.) Conservation Archaeology. New York: Academic Press, him. 63-72.

McGimsey III, Charles R.1978.Cultural Resources Management-Archaeology Plus. Dalam Charles L. Redman et al. (eds.), Social Archaeology Beyond Subsistence and Dating New York:Academic Press hlm.415-419

Sedyawati,Edy.1994.Pokok-pokok ketentuan dan permasalahan bangunan Cagar Budaya. Diskusi Panel: Mencari Pola Penerapan UU no. 5 Th. 1992 bagi Kawasan dan Ba. ngunan bersejarah di Surabaya sebagai Kota Pahlawan. Surabaya.

Uka,Tjandrasasmita.1995. Strategi pelestarian benda cagar budaya: Hubungannya dengan Arkeologi. Seminar Nasional Metodologi Riset Arkeologi. Depok:Fakultas Sastra UI 
Untoro Dradjat, Hari.1995. Manajemen Sumberdaya Budaya Mati. Seminar Nasional Metodologi Riset Arkeologi Depok:FS-UI.
Willey, G. R. dan P. Phillips (eds.). 1958. Mothod and Theory in American Archaeology. Chicago: University of Chicago Press. 